EVS26

Los Angeles, California, May 6-9, 2012

\title{
Ethylmethoxyethyl Sulfone Viability for Lithium Ion Battery Electrolytes
}

\author{
Dee Strand $^{1}$, Doug Brune ${ }^{1,}$ Oktay Uzun ${ }^{1}$, Steven Kaye ${ }^{2}$, Kevin Gering ${ }^{3}$ \\ ${ }^{1}$ The Dow Chemical Company, Building 1702, Midland, MI 48674, strandda@dow.com \\ ${ }^{2}$ Wildcat Discovery Technologies \\ ${ }^{3}$ Idaho National Lab
}

\begin{abstract}
Development of a practical, low cost high voltage electrolyte to enable lithium ion battery (LIB) operation above 4.5V will enable high energy density cells for vehicle applications. Towards that end, Dow Energy Materials is investing in programs to develop safe, cost-effective, high voltage electrolyte solutions. This effort leverages core capabilities of Dow’s large R\&D organization, such as fundamental modeling, low cost synthesis methods, and combinatorial formulation development. A practical solution to a high voltage electrolyte formulation requires all of these elements for success. This multi-faceted approach was utilized by Dow to determine the viability of ethylmethoxyethyl sulfone (EMES) as a high voltage electrolyte in full lithium ion cells.

Keywords: lithium battery, electrolyte, materials
\end{abstract}

\section{Introduction}

Development of a practical, low cost high voltage electrolyte to enable lithium ion battery (LIB) operation above $4.5 \mathrm{~V}$ will enable high energy density cells for vehicle applications. Towards that end, Dow Energy Materials is investing in programs to develop safe, costeffective, high voltage electrolyte solutions. This effort leverages core capabilities of Dow's large R\&D organization, such as fundamental modeling, low cost synthesis methods, and combinatorial formulation development. A practical solution to a high voltage electrolyte formulation requires all of these elements for success. This multi-faceted approach was utilized by Dow to determine the viability of ethylmethoxyethyl sulfone (EMES) as a high voltage electrolyte in full lithium ion cells.

LaTeX users: please provide title, authors, abstracts and keywords in the appropriate sections. For other programs, please follow the instructions in the abstract section.

\section{Results and Discussion}

Sulfones have been widely explored as potential high voltage materials, including EMES.[1,2,3] Some sulfone based electrolytes can demonstrate voltage stability up to $5 \mathrm{~V}$, but suffer from high viscosity, low conductivity, and inability to form SEI films on the LIB anode. Physical properties for EMES are shown in Fig. 1. In fact, HOMO calculations for many of these materials are well above $5 \mathrm{~V}$ making them particularly attractive as electrolyte candidates. Calculated LOMO values are typically around $1 \mathrm{~V}$ which are well above the potential of lithiated graphite, thereby requiring formation of a stable solid electrolyte interface (SEI) for good cycle life. EMES was selected as a candidate for high voltage evaluation by Dow due to its relatively low volatility, high flash point, high thermal stability, and reported stability of 
greater than $5 \mathrm{~V}$ on inert electrodes. The evaluation reflects a methodology of candidate screening using models, low cost synthesis, and combinatorial formulation experiments used by Dow.

\begin{tabular}{|c|c|c|c|}
\hline $\begin{array}{c}\text { Density } \\
\left(@ 5^{\circ} \mathrm{C}\right)\end{array}$ & $\begin{array}{c}\text { Molecular } \\
\text { Weight }\end{array}$ & $\begin{array}{c}\text { Viscocity } \\
\left(@ 25^{\circ} \mathrm{C}\right)\end{array}$ & $\begin{array}{c}\text { Conductivity } \\
\left(@ 25^{\circ} \mathrm{C}\right)\end{array}$ \\
\hline $1.13 \mathrm{~g} / \mathrm{cm}^{3}$ & 152.2 & $9.6 \mathrm{cP}$ & 1.3 \\
\hline \multicolumn{5}{|c|}{} & \multicolumn{1}{|c|}{} \\
\hline Freezing pt & $\begin{array}{c}\text { Boiling pt } \\
\text { (@ 1 bar) }\end{array}$ & Flash pt & $\begin{array}{c}\text { Dielectric } \\
\text { constant }\end{array}$ \\
\hline $2^{\circ} \mathrm{C}$ & $286^{\circ} \mathrm{C}$ & $130^{\circ} \mathrm{C}$ & 30. \\
\hline
\end{tabular}

Figure 1. EMES demonstrates low volatility and high flash point

Initial cycling to $5 \mathrm{~V}$ of EMES on $\mathrm{LiMn}_{2} \mathrm{O}_{4}$ (LMO) cathode vs. lithium indicated that EMES alone was not as stable as a standard carbonate formulation of ethylene carbonate and ethylmethyl carbonate (EC/EMC), as shown in Fig. 2. Furthermore, the rate performance when cycled in a $\quad \mathrm{LiNi}_{\mathrm{x}} \mathrm{Mn}_{\mathrm{y}} \mathrm{Co}_{\mathrm{z}} \mathrm{O}_{2} \quad$ (NMC) cathode/graphite anode cell was much poorer than the control EC/DEC formulation, presumably due to the high viscosity and low conductivity (Fig. 3).

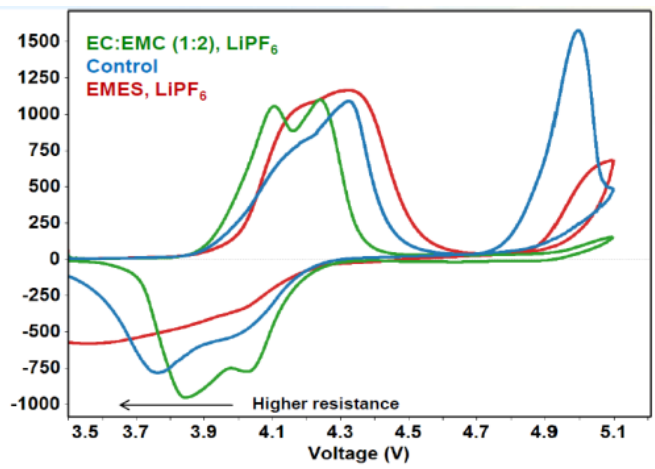

Figure 2. EC/EMES outperforms EMES at $5 \mathrm{~V}$ on $\mathrm{LMO}$

While 100\% EMES does not demonstrate adequate performance, an assessment of its use with co-solvents and additives is necessary to fully evaluate its potential usefulness. Formulation studies are inherently difficult due to the large number of variables including choice of co-solvent(s), ratios of solvents, salt concentration, and so forth. Therefore, Dow uses a combination of modeling and high throughput approaches to conclude at some confidence level that a material is viable or not. The Advanced Electrolyte Model (AEM) developed by K. Gering at INL was used to predict which combinations of solvents and salts, along with ratios of them, would result in the lowest viscosity, highest conductivity formulations.[4] This allows the elimination of many experiments on formulations with little promise of success.

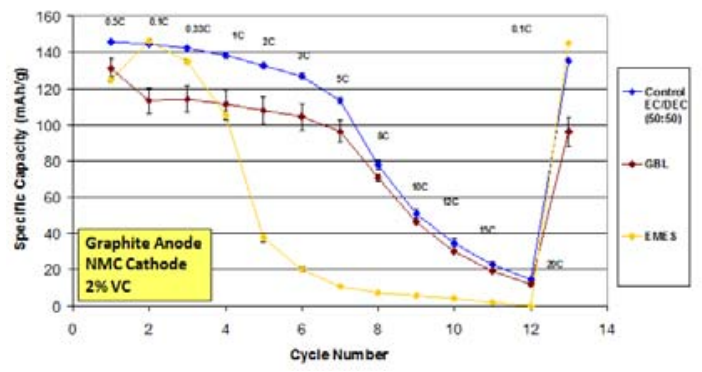

Figure 3. Poor C-rate performance of EMES due to high viscosity and low conductivity

Once the experimental design is defined with appropriate co-solvents, salts, etc., cell performance is determined and the favorable formulation space is defined. Examples of combinations are shown in Fig. 4 and Fig. 5 where EMES is evaluated with varying co-solvents against different cathodes and anodes.

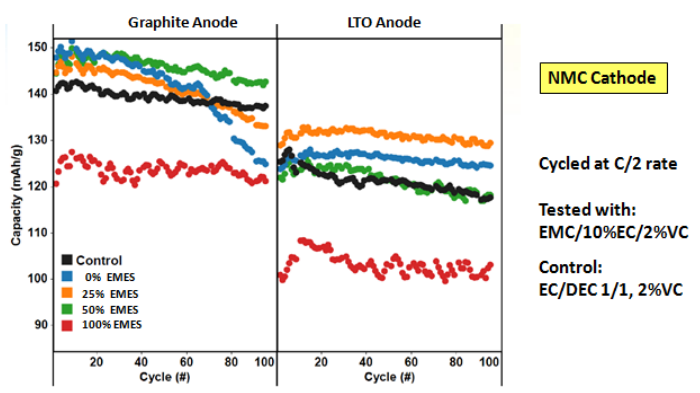

Figure 4. EMES improves NMC cycle life with EC/EMC co-solvent

While the high voltage value proposition of EMES was not demonstrated in this study, a number of interesting formulations were defined which improved cycle life on standard electrode materials. Without a "complete" approach to evaluation of high voltage candidates, including modeling, formulation science, and electrochemical screening, performance attributes of new electrolyte candidates will be missed. 


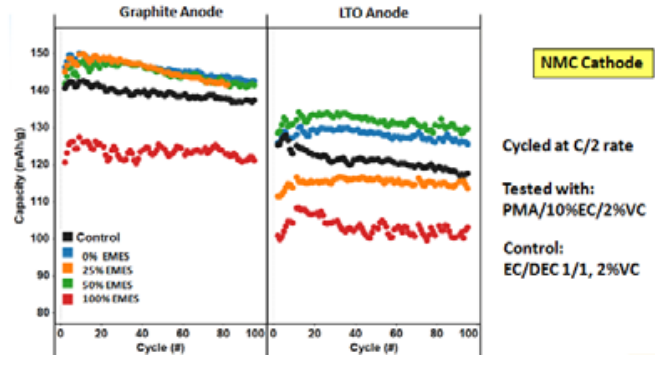

Figure 5. Some EMES/PMA blends demonstrate improved NMC cycle life (PMA = propylene glycol methyl ether acetate)

Finally, Dow Chemical has extensive experience in developing low cost manufacturing routes for new chemistries. An approach for low cost EMES was developed, which can be implemented if warranted. Extensive work at Dow is being done on novel new chemistries that show promise as high voltage candidates using this methodology. It is anticipated that other benefits of candidates will be identified that will provide value to the LIB market.

\section{Conclusions}

Investigation of potential $5 \mathrm{~V}$ electrolyte candidates is a complex undertaking best accomplished by a methodology including modelling, physical property screens, and electrochemical testing with a variety of battery materials. While EMES ultimately did not yield adequate high voltage performance in batteries, this methodology does demonstrate some regimes in which EMES may provide advantages. Dow's future work in $5 \mathrm{~V}$ electrolyte discovery uses these approaches to ensure that all performance attributes of potential candidates are determined.

\section{References}

[1] X.G. Sun et al., New sulfone electrolytes for rechargeable lithium batteries. Part I. Oligoether-containing sulfones, Electrochemistry 7(2005), 261-266.

Communications,

[2] Jow et al., DOE Merit Review 2009, High Voltage Electrolytes for Li-ion Batteries, http://www1.eere.energy.gov/vehiclesandfu els/resources/proceedings/2009_merit_revie w.html, accessed on 2012-01-23

[3] Jow et al., DOE Merit Review 2011, High Voltage Electrolytes for Li-ion Batteries, http://www1.eere.energy.gov/vehiclesandfue
Is/resources/proceedings/2011 merit review. html, accessed on 2012-1-23

[4] K. Gering, DOE Merit Review 2008, Update on Electrolyte Modeling with Emphasis on Low Temperature Performance, http://www1.eere.energy.gov/vehiclesandfuel s/resources/proceedings/2008_merit_review.h tml, accessed on 2012-1-23

\section{Author}

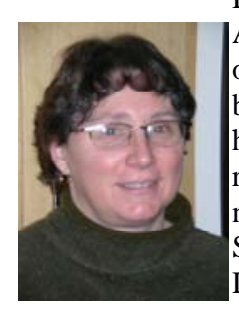

Dee Strand obtained a $\mathrm{PhD}$ in Analytical Chemistry from University of Wisconsin-Madison in 1989, and began work at Dow in that year. She has held a variety of positions in research and development, as well as new business development at Dow. She is currently a Research Fellow in Dow Energy Materials. 